\title{
Dysthyroidism in Elderly Subjects
}

\author{
Diedhiou Demba*, Diallo Ibrahima Mané, Gadji Fatou Kiné, Sow Djiby, \\ Ndour Michel Assane, Barrage Ahmed Limane, Thioye Elhadji Mamadou Moussa, \\ Ka-Cissé Mariama, Sarr Anna, Ndour-Mbaye Maimouna
}

\begin{abstract}
Department of Internal Medicine II, University Hospital Center of Dakar, Cheikh Anta Diop University, Dakar, Senegal
Email: ^dembadiedhiou1976@gmail.com, ibrahimamanediallo@hotmail.fr, kinegadji@gmail.com,

drdjiby@yahoo.fr,michelassanendour@yahoo.fr,limaneab@gmail.com, elthioye92@gmail.com,

marikacisse@gmail.com, mayoumbaye@gmail.com, annasarr@orange.sn
\end{abstract}

How to cite this paper: Demba, D., Mané, D.I., Kiné, G.F., Djiby, S., Assane, N.M., Limane, B.A., Moussa, T.E.M., Mariama, K.-C., Anna, S. and Maimouna, N.-M. (2020) Dysthyroidism in Elderly Subjects. Open Journal of Internal Medicine, 10, 181-189. https://doi.org/10.4236/ojim.2020.102019

Received: December 25, 2019

Accepted: May 16, 2020

Published: May 19, 2020

Copyright $\odot 2020$ by author(s) and Scientific Research Publishing Inc. This work is licensed under the Creative Commons Attribution International License (CC BY 4.0).

http://creativecommons.org/licenses/by/4.0/

\begin{abstract}
Introduction: Aging is associated with an anatomical and functional heterogeneity of the thyroid which varies according to the iodized status. The aim was to describe the clinical, etiology and therapeutic profile of dysthyroidism in elderly subjects in the internal medicine at the Abass Ndao University Hospital. Patients and methods: This was a retrospective, descriptive and analytical study, including all subjects aged 60 and over followed from January 1, 2010 to December 31, 2019 (10 years) for thyroid disease. Results: 371 Patients were collected with a prevalence of $3.8 \%$. The sex ratio was 0.15 and the mean age was 65.3 years. The circumstances of discovery of the disease were a grade 2 - 3 goiter (62.5\%), exophthalmos (24.5\%), thyrotoxicosis (56.6\%), a symptom of low metabolism (5.4\%), a cervical compression (10.8\% including $8 \%$ of dysphasia), and a cardiothyreosis (9.4\%). It was hyperthyroidism (65.2\%), and hypothyroidism (7.2\%). The main etiologies were toxic multinodular goiter (33.2\%), Graves's disease (29.6\%), euthyroidism nodular goiter (26.8\%), toxic adenoma (2.4\%), and Hashimoto's thyroiditis (6.7\%). The compressive manifestations were exclusive of nodular goiter. Among the 35 cases of cardiothyreosis, there was a rhythm and conduction disorder in 25 cases $(6.7 \%)$ and the underlying thyreopathy was a toxic nodular goiter in $57.1 \%$. Thyroidectomy involved $44.7 \%$ of patients, including $32.6 \%$ of Graves' disease, $48.3 \%$ of toxic nodular goiter, and $61.8 \%$ of nodular goiter in euthyroidism. We found 02 cases of papillary carcinomas on multinodular goiter. Conclusion: In our hospital series, there is variability in the clinical manifestations of dysthyroidism in the elderly. Complications, mainly cardiac and compressive, remain a major reason for consultation. Toxic nodular goiter is preponderant and its management, especially radical, must be multidisciplinary and according to the profile.
\end{abstract}




\section{Keywords}

Elderly, Dysthyroidism, Internal Medicine, Dakar

\section{Introduction}

Aging is a physiological process that is associated with anatomical and functional changes in the body. These non-enzymatic molecular alterations of proteins lead to an alteration of their structural and functional properties. This phenomenon participates in cell and tissue aging and, therefore, in the general aging of the organism [1]. It has been shown that aging is associated with exhaustion of most of the hormonal and enzymatic secretory functions [2]. This exhaustion is due to a loss of protein activity after glycation or carbamylation [3]. Endocrine functions in general and especially thyroid gland are not immune to this upheaval. Thyroid pathology is the most common endocrinopathy in the elderly. Aging is associated with complex changes in thyroid function that occur at several levels of regulation. The secretion of thyroid hormones is generally within the lower limits of the usual values. The two most significant changes are the shift in the distribution of the thyroid-stimulating hormone (TSH) to higher values, resulting in an increase in the upper limit of normal TSH levels from 4.5 to $6 \mu \mathrm{UI} / \mathrm{mL}$ after 70 years and $7.5 \mu \mathrm{IU} / \mathrm{mL}$ after 80 years. Thyroid pathologies affecting the anatomy (goiter, nodules, cancer) or the function (hyperthyroidism or hypothyroidism) of the thyroid are frequent especially in the elderly [4]. In the event of dysthyroidism, it remains in general rough or masked by the symptoms related to aging. The phenomena of aging and these anatomical consequences mean that diagnosis is not always easy, in a geriatric context [2]. These considerations have motivated this retrospective work, which aims to determine the clinical, biological and progressive characteristics of dysthyroidism in the elderly at the Abass Ndao hospital center.

\section{Patients and Methods}

It was a retrospective, descriptive study conducted from January 1, 2010 to December 31, 2019 (10 years). The study was carried out at Clinique Médicale II at the Center Hospitalier University of Abass Ndao. It focused on subjects aged 60 and over with thyroid disease and followed in internal medicine. Patient records were used to supplement data useful for the study. Incomplete clinical and/or biological records were not included. The pre-established sheet which served as the basis for the collection related to the following elements:

- Epidemiological and clinical aspects: Age, gender, other associated pathologies, time limit of the consultation. The goiter was classified into 4 grades according to the classification of the World Health Organization [5]. Graves's orbitopathy was characterized according to the consensus of the European Group on Graves Orbitopathy [6]. We also looked for other clinical manifestations of 
the disease. These were clinical signs of thyrotoxicosis, hypo metabolism symptoms, signs of cervical compression (dysphasia, dysphonia, dyspnea, cyanosis, neck pain, repetitive laryngeal irritation), signs related to complications of hyperthyroidism (cardiothyreosis, acute thyrotoxic crisis), or hypothyroidism (arteritis, pericardial effusion, coma).

- Paraclinical examinations: The plasma values of free tetra iodothyronine (free T4), free triiodothyronine (free T3) and ultra-sensitive thyroid-stimulating hormone (TSHus) were evaluated at inclusion. The biochemical standards of our laboratory were [0.17 to $4.05 \mathrm{mIU} / \mathrm{l}$ ] for TSHus, [ 9 to $22 \mathrm{pmol} / \mathrm{l}$ ] for free T4 and [2.5 to $5.8 \mathrm{pmol} / \mathrm{l}]$ for free T3. Diffuse goiter benefited from additional autoimmune exploration. These were anti-thyroperoxidase and anti TSH receptor antibodies. Cervical ultrasound was systematic in all cases. It made it possible to appreciate the size of the thyroid, its echogenicity and homogeneity, the type of vascularization, the existence and the character of the nodules.

We retained hyperthyroidism in front of a persistent decrease in TSHus $<0.01$ $\mathrm{mIU} / \mathrm{l}$ with or without increase of the thyroid hormones. Hypothyroidism was retained in the face of a persistent increase in TSHus $\geq 10 \mathrm{mIU} / \mathrm{l}$ with or without a decrease of the thyroid hormones. The diagnosis of Graves' disease was made before any hyperthyroidism associated with one or more of the following signs: graves orbitopathy, vascular goiter, pretibial myxedema and incidentally an increase of the anti TSH receptor antibodies (TRAKS) or a diffuse attachment to the thyroid in scintigraphy. Hashimoto's thyroiditis was defined by any hypothyroidism associated with an increase in anti-thyroperoxidase antibodies (anti TPO) with or without diffuse goiter. The other inflammatory thyroiditis was Dequervain thyroiditis (acute inflammatory goiter and infectious syndrome), thyroid abscess.

The diagnosis of nodular goiter was retained in the presence of single nodular formation (single nodule) or multiple nodule (multinodular goiter) on a normal or enlarged thyroid gland. Goiter was toxic nodular in front of a nodular goiter associated with hyperthyroidism. In this specific case, thyroid scintigraphy confirmed the toxic nature of the nodule identified on ultrasound. In case of thyroid nodule, a needle aspiration with a histological study was requested. Other explorations such as blood sugar, hemogram, liver function, EKG were requested according to the clinical profile. The diagnosis of cardiothyreosis is based on the presence of the association of thyrotoxicosis and various cardiovascular disorders such as heart failure, coronary artery disease, rhythm or conduction disorders.

- Treatment and evolution of thyroid pathology: We studied the treatment carried out. These were mainly medical treatment (synthetic antithyroid or L-thyroxin or anti inflammatory), surgery, radioactive iodine and abstention from therapy. The course of thyroid disease was also assessed.

- Data analysis: For the descriptive part, the data were presented as a percentage for the qualitative variables and as an average for the quantitative variables. The data entry and processing was carried out by software Epi info version 7.2.2.2. 


\section{Results}

\subsection{Epidemiological Aspects}

We included 371 patients out of 9750 cases of dysthyroidism received in 10 years. The prevalence was of $3.8 \%$. The female gender was predominant ( 321 women) with a sex ratio of 0.15 . The mean age was 65.3 years (range 60 and 90). The other associated pathologies were 76 cases of arterial hypertension (20.5\%), 15 cases of diabetes mellitus (4\%). The average time limit of consultation was 29.8 months (range 6 and 120 months).

\subsection{Clinical Aspects}

The circumstances of diagnosis of thyroid disease were mainly a goiter (291 cases, 78.4\%), exophthalmos (91 cases, $24.5 \%$ ), a cervical compression (40 cases, $10.8 \%$ ), and cardiothyreosis (35 cases, 9.4\%). The goiter was at grade 2 to 3 in 232 subjects $(62.5 \%)$. Compression was dominated by the dysphasia in 30 cases (8\%). The main manifestations of thyrotoxicosis were weight loss (130 cases, $35 \%)$, palpitations (140 cases, $37.7 \%$ ), insomnia (100 cases, $26.9 \%$ ), tremors ( 80 cases, $21.5 \%$ ), fatigability (78 cases, $21 \%$ ). The main signs of hypothyroidism were skin and phanerian disorders (15 cases, 4\%), constipation (15 cases, 4\%) and myxedematous syndrome (5 cases, $1.3 \%$ ). Among the 35 subjects with cardiothyreosis, 25 cases (6.7\%) had a rhythm and conduction disorder. Table 1 shows the epidemiological and clinical profile of dysthyroidism in the elderly.

\subsection{Paraclinical and Etiological Aspects}

Functionally, it was hyperthyroidism (242 cases, $65.2 \%$ ), hypothyroidism (27 cases,

Table 1. Epidemiological and clinical profile of dysthyroidism in the elderly.

\begin{tabular}{lc}
\hline Parameters studied & Workforce \\
\hline Epidemiological data & 371 \\
Effective & $50(13.5 \%)$ \\
Males & 0.15 \\
Sex ratio & 65.3 years \\
Mean age & $38(10.2 \%)$ \\
Family history of thyropathy & 29.8 months \\
Time limit of consultation & \\
Circumstances of diagnosis & $210(56.6 \%)$ \\
Thyrotoxicosis & $20(5.4 \%)$ \\
Hypo metabolism & $40(10.8 \%)$ \\
Cervical compression & $35(9.4 \%)$ \\
Cardiothyreosis & $91(24.5 \%)$, \\
Graves orbitopathy & $232(62.5 \%)$ \\
Goiter in grade 2 and 3 &
\end{tabular}


7.2\%). The cervical ultrasound and thyroid scintigraphy data found a diffuse goiter in 120 cases $(32.3 \%)$, a multinodular goiter in 216 cases $(52.2 \%)$, a single nodule in 32 cases $(8.6 \%)$ and an atrophied thyroid in 03 cases (1\%). The main etiologies were toxic multinodular goiter (123 cases, 33.2\%), Graves' disease (95 cases, $25.6 \%$ ), multinodular goiter in euthyroidism (76 cases, $20.4 \%$ ), Hashimoto thyroiditis ( 25 cases, $6.7 \%$ ), a simple goiter (02 cases, $0.5 \%$ ). Table 2 shows the functional and etiological profile of dysthyroidism.

The sex ratio and the average age of the patients were respectively of ( 0.25 and 64 years) in Graves' disease, of ( 0.56 and 66.4 years) in multinodular goiter, of ( 0.17 and 67.4 years) in the thyroid nodule and of ( 0.13 and 65.1 years) in Hashimoto's thyroiditis. All the compressive manifestations were found in nodular goiter. Among the 35 cases of cardiothyreosis, the average age was 65.9 years and the underlying disease was 15 cases (42.8\%) of Graves' disease and 20 cases (57.1\%) of toxic multinodular goiter.

\subsection{Therapeutic and Evolutionary Aspects}

Thyroidectomy involved in 166 cases (44.7\%) of which 32.6\% (31 cases) of subjects with Graves' disease, $40 \%$ (6 cases) of cases with nodular goiters basedowfiés, $46.3 \%$ (57 cases) cases with toxic multinodular goiter, $60.5 \%$ (46 cases) of multinodular goiter cases in euthyroidism, $88 \%$ (8 cases) of patients with toxic adenoma and $70.8 \%$ (17 cases) of simple nodules. We found in histology exploration 02 cases of papillary carcinomas on multinodular goiter in euthyroidism. Two cases of death were recorded in connection with cardiothyreosis.

\section{Discussion}

In Africa, few works have been interested in thyroid pathology in the elderly.

Table 2. Etiological and therapeutic profile of dysthyroidism in the elderly.

\begin{tabular}{lll}
\hline Parameters studied & Workforce \\
\hline Effective & & 371 \\
Functional disorders & \\
& Hyperthyroidism & $242(65.2 \%)$ \\
& Hypothyroidism & $27(7.2 \%)$ \\
& Euthyroidism & $102(27.5 \%)$ \\
Etiologies & & \\
& Graves' disease & $94(25.6 \%)$ \\
& Nodular goiter with Graves disease & $15(4 \%)$ \\
& Hashimoto Thyroiditis & $25(6.7 \%)$ \\
& Toxic multinodular goiter & $123(33.2 \%)$ \\
& Toxic adenoma & $9(2.4 \%)$ \\
& Multinodular goiter in euthyroidism & $76(20.4 \%)$ \\
Simple nodule & $24(6.4 \%)$ \\
\hline
\end{tabular}


Most of them were limited to a characterization specific to hypothyroidism or hyperthyroidism [7]. This explains the absence of comparative epidemiological data. A South African study reported frequencies ranging from $0.4 \%$ to $9 \%$ [8]. Elsewhere in Europe and the United States, the prevalence of dysthyroidism in the elderly varies according to country, series, iodine status and diagnostic methods [9]. This difference could be explained by the existence of geriatric units, through greater accessibility and sometimes a systematization of biological explorations in the elderly European population. In our study the predominance was female and the average age around the sixth decade. In Europe, the average age was at the seventh or even the eighth decade [10] [11].

In the elderly, due to senescence, a number of symptoms are masked or absent during dysthyroidism [12]. The diagnoses are made thanks to the dosage of TSH recommended in first intention to evaluate the thyroid function. In the elderly, the assay can be performed as part of the overall assessment of cognitive impairment or dementia or in the presence of clinical signs suggestive of dysthyroidism. This last indication can be relatively broad, justified by the differences reported in the clinical expression of dysthyroidism proven after 70 years [13] [14]. In most cases series, the symptoms are summed up as specific signs of the disease or the complications that preferentially affect the heart and the brain [15] [16]. In our study, the most common signs were goiter (78.4\%), exophthalmos (24.5\%), cervical compression (10.8\%) and cardiothyreosis (35 cases, 9.4\%).

On the functional level, we find in an English study $92.3 \%$ of euthyroidism, $0.3 \%$ to $1 \%$ of hyperthyroidism and $0.3 \%$ to $6.2 \%$ of hypothyroidism [10]. In a summary work reported by Retomaz et al. [9], the prevalence of true hypothyroidism was from $0.5 \%$ to $7.6 \%$. We report $7.2 \%$ of hypothyroidism cases. As in our series, Hashimoto's disease remains the predominant aetiology [9]. With the gradual onset of hypothyroidism, the symptoms may be difficult to assess. Several classic signs of hypothyroidism can be attributed to aging. Finally, Hypothyroidism can be associated with cardiovascular dysfunction and especially with an increased risk of atherosclerosis [17]. In our series, no case of cardiac complications related to hypothyroidism was found.

Graves's disease and especially toxic nodular goiter constitute the two main etiologies of hyperthyroidism [18]. According to Retomaz et al. [9], the prevalence of hyperthyroidism is $0.02 \%$ to $2.5 \%$ after 60 years. The two most common causes are toxic nodule and multinodular goiter in regions with iodine deficiency, and Graves' disease in regions with normal or high iodine status. Cardiac manifestations are not uncommon [19]. They are often in the foreground with complications such as atrial fibrillation and heart failure [20]. Our study found cardiothyreosis in $9.4 \%$ of cases. The underlying disease was mainly toxic lump goiter $(57.1 \%)$ or Graves' disease $(42.8 \%)$.

The nodularity is a major characteristic of the aging of the thyroid. Its prevalence varies according to the iodized status and the sensitivity of detection techniques. Based on autopsy studies, the prevalence of nodules has been estimated 
at $90 \%$ in women over the age of $70 \%$ and $60 \%$ in men over the age of 80 [21]. In subjects with multinodular goiter, there is a risk of progression to hyperthyroidism due to the autonomy of one or more nodules. Among our 247 patients with nodular goiter, 59.5\% had true hyperthyroidism. In our study, 02 papillary thyroid carcinomas were diagnosed on multi-nodular goiter. Papillary carcinomas were more common in solitary nodules of the thyroid in the elderly.

The treatment of hyperthyroidism is preferably radical in the elderly to avoid the risk of recurrence with cardiac repercussions, the effects of which can be deleterious at an advanced age. It can be surgery or iodine therapy 131. The prescription of synthetic antithyroid drugs is limited to a short period for the return to euthyroidism before radical treatment [22].

\section{Conclusion}

Dysthyroidism in the elderly is characterized by clinical and progressive variability. The etiologies were mainly dominated by 3 main entities: Graves' disease, nodular goiter, autoimmune thyroiditis. The deaths found were mainly related to cardiovascular complications which were the prerogative of hyperthyroidism. There was no correlation between the type of goiter and the histological nature of the neoplasias found. A prospective study on a larger scale in the population could allow deciding on the best profile of thyroid pathology in Senegal.

\section{Limitations of the Study}

The study was conducted in university hospital. It may not represent the community situation which is important in terms of knowledge and practice.

This is a single center study. Large scale multicenter study is needed to represent the national situation.

This is a retrospective study conducted from patient's files. Only the complete files were included which makes a loss of data.

This kind of work doesn't require in our country the approval of ethic committee because it is a retrospective work on patient's file.

\section{Conflicts of Interest}

The authors have nothing to disclose.

\section{References}

[1] Stéphane, J., Aurore, D., Laëtitia, G. and Philippe, G. (2017) Protein Molecular Aging: Which Role in Physiopathology? Medical Sciences, 33, 176-182. https://doi.org/10.1051/medsci/20173302013

[2] Racaru-Honciuc, V., Betea, D. and Scheen, A.J. (2014) Hormonal Deficiencies in the Elderly: Is There a Place for a Replacement Therapy? Revue Médicale Suisse, 10, 1555-61.

[3] Boyd, A.C., Abdel-Wahab, Y.H., McKillop, A.M., et al. (2000) Impaired Ability of Glycated Insulin to Regulate Plasma Glucose and Stimulate Glucose Transport and Metabolism in Mouse Abdominal Muscle. Biochimica et Biophysica Acta, 1523, 
128-134. https://doi.org/10.1016/S0304-4165(00)00113-6

[4] Retornaz, F., Castinetti, F., Molines, C. and Oliver, C. (2013) Thyroid in the Elderly (Part 1). La Revue de Médecine Interne, 34, 623-627.

https://doi.org/10.1016/j.revmed.2012.11.011

[5] World Health Organization, United Nation Children's Fun \& International Council for Control of Iodine Deficiency Disorders (1994) Indicators for Assessing Iodine Deficiency Disorders and the Control through Salt Iodization. Geneva, 1-55.

[6] Bartalena, L., Baldeschi, L., Dickinson, A.J., et al. (2008) Consensus Statement of the European Group on Graves' Orbitopathy (EUGOGO) on Management of GO. European Journal of Endocrinology, 158, 273-285. https://doi.org/10.1530/EJE-07-0666

[7] Sarr, A., Ndour-Mbaye, M., Diop, S.N., Diédhiou, D. and Ka-Cissé, M. (2010) Hyperthyroidism in the Elderly: Clinical Aspects and Causes of 33 Dakar Cases. Revue CAMES, 11, 7-9.

[8] Muller, G.M., Levitt, N.S. and Louw, S.J. (1997) Thyroid Dysfunction in the Elderly. South African Medical Journal, 87, 1119-1123.

[9] Retornaz, F., Castinetti, F., Molines, C. and Oliver, C. (2013) Thyroid in the Elderly (Part 2). La Revue de Médecine Interne, 34, 623-627. https://doi.org/10.1016/j.revmed.2012.11.011

[10] Parle, J.V., Franklyn, J.A., Cross, K.W., Jones, S.C. and Sheppard, M.C. (1991) Prevalence and Follow-Up of Abnormal Thyrotrophin (TSH) Concentrations in the Elderly in the United Kingdom. Clinical Endocrinology, 34, 77-83. https://doi.org/10.1111/j.1365-2265.1991.tb01739.x

[11] Teissier, M.P., Archambeaud-Mouveroux, F., Gaillard, S. and Laubie, B. (1999) Screening for Thyroid Dysfunction in Older French Hospitalized Patients. Annales d'Endocrinologie, 60, 23.

[12] Goichot, B. and Luca, F. (2011) Subclinical Thyroid Dysfunction. La Presse Médicale, 40, 1132-1140. https://doi.org/10.1016/j.lpm.2011.09.009

[13] Doucet, J., Trivalle, C., Chassagne, P., Perol, M.B., Vuillermet, P., Manchon, N.D., et al. (1994) Does Age Play a Role in the Clinical Presentation of Hypothyroidism? Journal of the American Geriatrics Society, 42, 984-986. https://doi.org/10.1111/j.1532-5415.1994.tb06592.x

[14] Trivalle, C., Doucet, J., Chassagne, P., Landrin, I., Kadri, N., Minard, J.F., et al. (1996) Difficulties in the Signs and Symptoms of Hyperthyroidism in Older and Younger Patients. Journal of the American Geriatrics Society, 44, 50-53. https://doi.org/10.1111/j.1532-5415.1996.tb05637.x

[15] Roberts, L., McCahon, D., Johnson, O., Haque, M.S., Parle, J. and Hobbs, F.D.R. (2018) Stability of Thyroid Function in Older Adults: The Birmingham Elderly Thyroid Study. British Journal of General Practice, 68, 718-725. https://doi.org/10.3399/bjgp18X698861

[16] Aronow, W.S. (1995) The Heart and Thyroid Disease. Clinics in Geriatric Medicine, 11, 219-229. https://doi.org/10.1016/S0749-0690(18)30292-1

[17] Cappola, A.R. and Ladenson, P.W. (2003) Hypothyroidism and Atherosclerosis. The Journal of Clinical Endocrinology \& Metabolism, 88, 2438-2444. https://doi.org/10.1210/jc.2003-030398

[18] Laurberg, P., Pedersen, K., Hreidarsson, A., Sigfusson, N., Iversen, E. and Knudsen, P. (1998) Iodine Intake and the Pattern of Thyroid Disorders: A Comparative Epidemiological Study of Thyroid Abnormalities in the Elderly in Iceland and in Jut- 
land, Denmark. The Journal of Clinical Endocrinology \& Metabolism, 83, 765-769. https://doi.org/10.1210/jcem.83.3.4624

[19] Barbesino, G. (2019) Thyroid Function Changes in the Elderly and Their Relationship to Cardiovascular Health: A Mini-Review. Gerontology, 65, 1-8. https://doi.org/10.1159/000490911

[20] Gambert, S.R. (1995) Hyperthyroidism in the Elderly. Clinics in Geriatric Medicine, 11, 181-188. https://doi.org/10.1016/S0749-0690(18)30290-8

[21] Denham, M.J. and Wills, E.J. (1980) A Clinico-Pathological Survey of Thyroid Glands in Old Age. Gerontology, 26, 160-166. https://doi.org/10.1159/000212409

[22] Kennedy, J.W. and Caro, J.F. (1996) The ABCs of Managing Hyperthyroidism in the Older Patient. Geriatrics, 51, 22-24, 27, 31-32. 